\title{
Intracapsular development and dispersal polymorphism in the predatory gastropod Ocenebra erinaceus (Linnaeus 1758)
}

\author{
Kathryn E. Smith ${ }^{1,2} \cdot$ Adam J. Reed $^{1} \cdot$ Sven Thatje $^{1}$
}

Received: 9 December 2014/Revised: 20 March 2015 / Accepted: 14 April 2015/Published online: 30 April 2015

(C) Springer-Verlag Berlin Heidelberg and AWI 2015

\begin{abstract}
Intraspecific polymorphism during development, such as poecilogony or dispersal polymorphism, has rarely been observed in the marine environment. The ecological advantages of this bet-hedging strategy, whereby the offspring from one species exhibit multiple developmental modes, include the potential for rapid colonization of new habitats while simultaneously achieving a degree of gene flow between populations. The muricid gastropod, Ocenebra erinaceus, is a common, shallow-water marine predator found across England and France. Historically, O. erinaceus caused significant damage to shellfisheries, but more recently it has been impacted by TBT-induced imposex. Despite the previous attention given to this species, little is known about its encapsulated development. Studying O. erinaceus egg capsules from the Solent, UK, we describe intracapsular development at $15{ }^{\circ} \mathrm{C}$, the in situ temperature at time of oviposition. Within each capsule, all embryos developed; no nurse eggs were present. Development was categorized into eight ontogenetic stages, although not all individuals displayed every stage; embryos hatched as either swimming late-pediveliger larvae or crawling juveniles after 59-69 days, indicating dispersal polymorphism to occur in this species. Swimming late-pediveliger larvae completed
\end{abstract}

Communicated by H.-D. Franke.

Kathryn E. Smith

kathryn@fit.edu

1 Ocean and Earth Science, University of Southampton, European Way, Southampton SO14 3ZH, UK

2 Present Address: Department of Biological Sciences, Florida Institute of Technology, 150 West University Boulevard, Melbourne, FL 32901, USA metamorphosis within $72 \mathrm{~h}$ of hatching. As O. erinaceus continues to recover from TBT pollution, dispersal polymorphism may facilitate a rapid expansion in both population size and range. If this occurs, $O$. erinaceus has the potential to, once again, become a serious problem for shellfisheries around Europe.

Keywords Bet-hedging · Muricid · Intracapsular development - Ocenebra erinaceus . Shellfisheries . Tributyltin · Dispersal polymorphism

\section{Introduction}

The dispersal capacity and the potential for range expansion in benthic marine invertebrates are directly related their developmental mode (Jablonski 1986; Poulin et al. 2001; Cowen and Sponaugle 2009). Pelagic development typically indicates a high dispersal potential through time spent in the plankton, whereas non-pelagic (benthic) development usually dictates a reduced dispersal capacity due to limited mobility during development (e.g. Pechenik 1999; Grantham et al. 2003). Although dispersal capacity is decreased, survival rate is generally greater for embryos with benthic development; these offspring are typically brooded by an adult or develop inside an egg capsule where nutritional reserves and some degree of protection are available (Vance 1973). In contrast, embryos exhibiting pelagic development, which are usually planktotrophic and with limited protection, often have reduced survival, and many individuals are lost in the plankton during development. Some species also exhibit mixed development, whereby all offspring undergo both a non-pelagic and pelagic stages during development (Vance 1973; Pechenik 1979; Jablonski 1986; Poulin et al. 2001). 
Although rarely observed, some marine invertebrates display intraspecific polymorphism in their developmental mode (e.g. Toonen and Pawlik 2001; Krug 2007; Oyarzun and Strathmann 2011). This may be observed as poecilogony, whereby offspring from the same individual or species exhibit multiple modes of development-i.e. pelagic or benthic — or as dispersal polymorphism whereby the offspring from one female, which have the same mode of development, have multiple morphs at hatching (Chia et al. 1996; Toonen and Pawlik 2001; Collin 2012). In the rare examples of dispersal polymorphism in marine invertebrates with benthic development, offspring display this trait by varying the timing of their metamorphosis to the benthos; some individuals hatch as crawling juveniles, while other individuals, often from the same egg capsule, spend a period of time in the plankton prior to settling (Krug 2007). Dispersal polymorphism and poecilogony are both forms of bet-hedging that allow species to retain some individuals for immediate recruitment into adult populations while simultaneously achieving a degree of dispersal. This increases the potential for offspring survival and may allow the species to achieve gene flow between populations while, at the same time, contributing to the parent population (Chia et al. 1996; Krug 2009).

It has been suggested that species exhibiting multiple modes of development can achieve range expansions more rapidly than species exhibiting a single mode of development (Elliot and Cornell 2012). Consequently, dispersal polymorphism and poecilogony may be associated with greater dispersal potential and ability to colonizing new environments, and may facilitate the range expansion of invasive species including predators (native or invasive) that may be damaging to local marine ecosystems or commercial fisheries. Additionally, such characteristics may accelerate the expansion of recovery of a previously declining species. Across many parts of Europe, the muricid gastropod Ocenebra erinaceus has historically caused significant damage to shellfisheries, including oyster and mussel beds (Hancock 1960). This species, which is native to Europe, is predominantly found in the subtidal and intertidal, around the UK and French coasts. Adults use their radula to drill a hole in the shell of their prey to gain access to the flesh (Hancock 1960; Laing and Spencer 2006). When present in large numbers, they can decimate entire shellfish beds. Throughout the 1970s-1990s, however, populations of $O$. erinaceus were highly impacted by tributyltin (TBT), which induced imposex in many gastropods (Oehlmann et al. 1992; Gibbs 1996). This species has a similar-or possibly higher-sensitivity to TBT as Nucella lapillus, the primary species used for monitoring TBT pollution within Europe, and prior to 1986 it was also used as a TBT monitoring tool (Huet et al. 1995; Oehlmann et al. 1996; Gibbs et al. 1997; Gibbs 2009). As populations of $O$. erinaceus declined, its impact on shellfisheries was reduced. Recent studies indicate that the proportion of sterile females in heavily polluted areas is still high and reaching over $75 \%$ (Gibbs 2009). Consequently, the recovery of these populations remains questionable. Assuming they do recover, O. erinaceus may, once again, become a serious problem for shellfisheries in European waters (Laing and Spencer 2006).

In order to comprehend the future status and potential impact of $O$. erinaceus on shellfisheries, it is important to understand their development. Embryos develop within individual egg capsules, which are laid directly onto a hard substrate by females during spring (Hancock 1960; Martel et al. 2004). Despite the attention this species has received in the past, initially as a pest to shellfisheries and later as a monitoring tool for TBT pollution, the intracapsular development of $O$. erinaceus has never been described fully. Hawkins and Hutchinson (1988) commented on a mucus plug in the mouth of each capsule, which dissolves when juveniles are ready to hatch, and Gibbs (1996) reported that all juveniles went through a short planktonic phase of up to 5 days following hatching. This latter observation indicates that offspring may have a mixed developmental mode. Evidence regarding whether embryos consume nurse eggs during development remains conflicting (Lebour 1937; Hancock 1956, 1960). Here, we describe the complete intracapsular development of $O$. erinaceus from a population collected from the south coast of England.

\section{Materials and methods}

\section{Collection and maintenance of egg masses}

In order to study the intracapsular development in $O$. erinaceus, approximately 30 adult whelks were randomly collected in mid-May 2012 from the Solent, UK $\left(50^{\circ} 39^{\prime} \mathrm{N}\right.$, $\left.001^{\circ} 37^{\prime} \mathrm{W}\right)$. Ocenebra erinaceus females spawn one clutch of egg capsules each year during spring (Hancock 1960; Martel et al. 2004). Collection took place at approximately 10-m water depth, using a beam trawl deployed from on board $R V$ Callista. Adults were maintained in a large outdoor tank with continuous seawater flow-through in the aquarium at the National Oceanography Centre, Southampton, and monitored daily. Adults ranged 27-33 mm in shell length. They were fed on scrap fish ad libitum three times each week. Egg capsule laying occurred on hard substrate in the aquaria, on the shells of other adult $O$. erinaceus, and on the walls of the aquaria, between the 16 May 2012 and 23 May 2012. Water temperature was recorded daily. During the laying period, water temperature ranged between 14 and $16{ }^{\circ} \mathrm{C}$. Each egg mass was removed from the aquaria approximately $24 \mathrm{~h}$ 
after laying had ceased, transferred individually to $1.8-1$ tanks, and maintained in an incubator at $15^{\circ} \mathrm{C}$ and for the duration of embryo development. In total, 13 egg masses were used in this investigation, each consisting of 11-34 (average 21) capsules.

\section{Embryonic development and intracapsular contents}

All egg masses were examined twice per week; one egg capsule was removed at random from each egg mass and its contents inspected. Capsules were bilaterally flattened, urnlike structures with a concave/convex face, as described by Hawkins and Hutchinson (1988) (Fig. 1a, b). Each individual egg capsule was connected to a hard substrate by a thin stem and a basal disc. The top of each capsule had a rounded face with a small, outward pointing plug. Upon removal, the length of each egg capsule (excluding the stem but including the plug) was measured using digital calipers $( \pm 0.01 \mathrm{~mm})$. The capsule was then dissected under a compound microscope; the number of embryos inside was counted, and the ontogenetic stage of each was described. Each individual embryo or juvenile was measured along the longest linear axis observed under a compound microscope. Measurements were taken to the nearest $\pm 0.01 \mathrm{~mm}$ using an eyepiece graticule. Prior to hatching, 16 capsules were randomly removed from across the egg masses and were placed in individual $100-\mathrm{ml}$ vials in order to investigate dispersal polymorphism. Upon hatching, the numbers of swimming late-pediveliger larvae and crawling juveniles from each capsule were counted. They were then observed once every $24 \mathrm{~h}$ and until no swimming latepediveligers remained. Ontogenetic stages were defined as egg, trochophore, early veliger, veliger, pediveliger, late pediveliger/pre-hatching juvenile, and swimming late-pediveliger/hatching juvenile; for descriptions see further below. Developmental timing was determined through comparison of the ontogenetic stages observed in all egg capsules and throughout development.

Change in number of embryos per capsule during development was examined in order to investigate whether all embryos completed development. To do this, an unpaired $t$ test was carried out to compare all capsules that were examined at egg stage $(n=45)$ and all capsules that were examined at the late-pediveliger/pre-hatching juvenile stage $(n=37)$. For both stages, this included capsules collected from at least 10 egg masses laid by multiple females. The relationship between capsule length and number of embryos per capsule was examined using regression analysis. Following the confirmation of no change in number of embryos per capsule during development, the contents of all egg capsules investigated through development were included in the analysis $(n=146)$.

\section{Results}

\section{Ontogenetic stages}

Eight early ontogenetic stages were identified (described below) although not all individuals displayed all eight stages. All eggs were fertilized and developed into embryos. They are therefore classified as 'fertilized eggs' for the ontogenetic description.

\section{Fertilized eggs}

Each capsule contains 21-80 (mean 48) pale yellow, spherical fertilized eggs that initially show no definition. No nurse eggs are present. The first cellular cleavage becomes evident within approximately $24 \mathrm{~h}$. Fertilized eggs have an average diameter of $587 \mu \mathrm{m}$ (range 540-680 $\mu \mathrm{m}$ ) (Fig. 2a; Table 1). They are visible within egg capsules for approximately 16 days (Fig. 2a; Table 1).

\section{Trochophore}

After 16-23 days, developing embryos become elongated and a translucent membrane becomes obvious around them. The outer membrane first separates from the developing embryo at the anterior and then at the posterior; the anterior separation is equal across the developing embryo, but the posterior separation is directional. Cilia are present but not obvious at the base of the anterior outer membrane separation. Pale yellow, oval-shaped larval kidneys become obvious on either side of the trochophore, approximately half way down the body and behind the anterior membrane separation. A white visceral mass then becomes visible posterior of the larval kidneys. Each trochophore has an average length of $717 \mu \mathrm{m}$ (range 660-800 $\mu \mathrm{m}$ ). Developing embryos remain within the trochophore stage for approximately 4 days (Fig. 2b; Table 1).

\section{Early veliger}

The early veliger remains elongated, and the body begins to extend sideways, beginning to fill the posterior section of the membrane. The anterior membrane separation flattens a little and extends laterally to form paired velar lobes with short marginal cilia. Larval kidneys remain obvious, but the positioning of them is more anterior, directly behind the velar lobes. Visceral mass also remains obvious. Early veligers are mobile and turn slowly in circles aided by the cilia. Each early veliger has an average length of $754 \mu \mathrm{m}$ (range 670-870 $\mu \mathrm{m}$ ). Developing embryos retain the characteristics of the early veliger stage for approximately 8 days (Fig. 2c; Table 1). 
Fig. 1 Intracapsular development in Ocenebra erinaceus. a Front view of egg capsule. b Side view of egg capsule with concave/convex face visible. c Crawling juvenile. d Swimming latepediveliger. e Juvenile with normal development (left) and juvenile with retarded development (right). The retarded juvenile is transparent and lacks shell. $p$ plug, de developing embryo, st stem, $b d$ basal disc, $s$ shell, $e$ eye, $t$ tentacle, $f$ foot, $p$ protoconch, $c$ cilia, $v l$ velar lobe, $s g$ siphonal groove
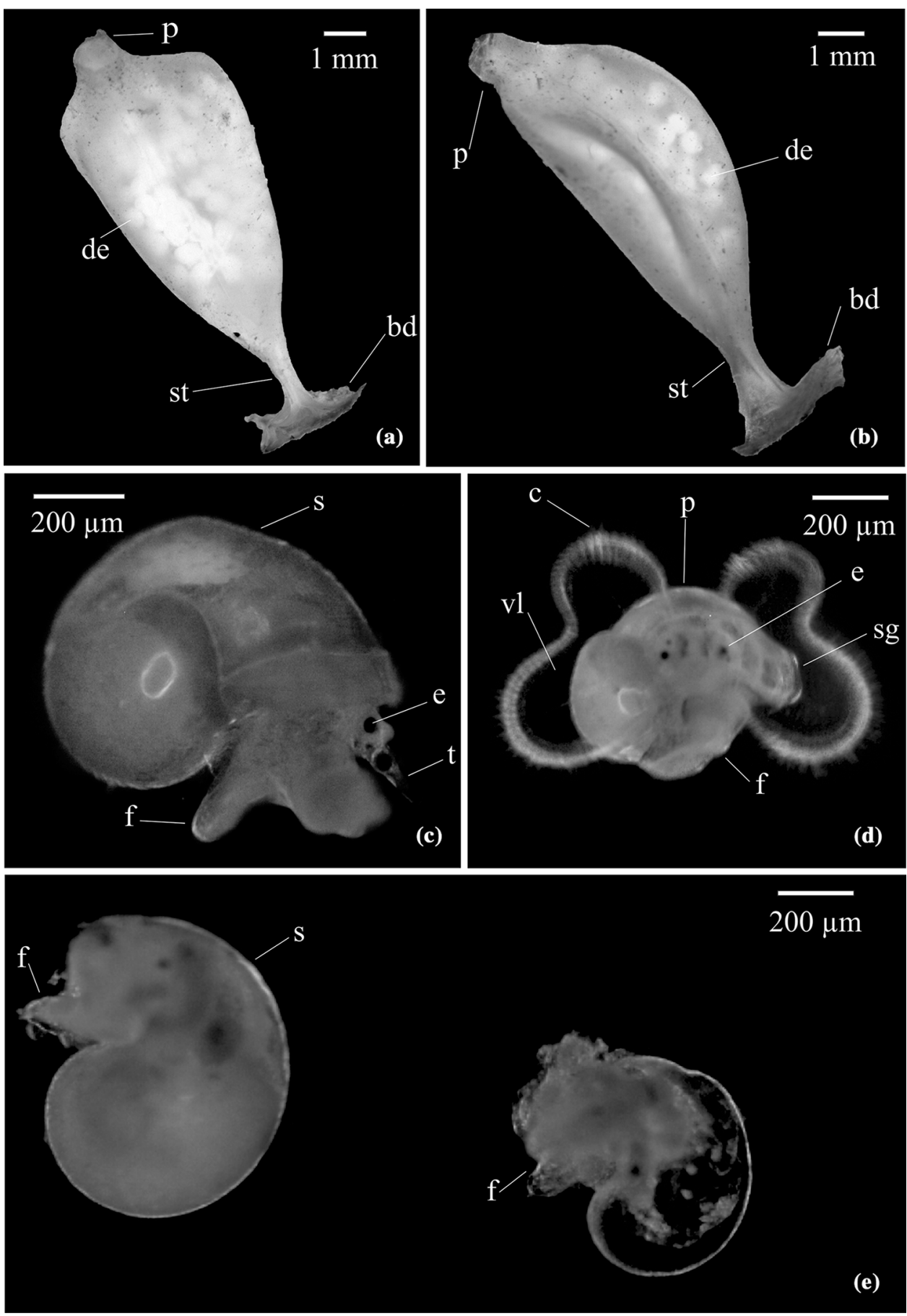

\section{Veliger}

As the embryo reaches the veliger stage of development, the body becomes more rounded and the transparent mantle edge and mantle cavity become obvious. The velar lobes become more defined and the cilia lining their edge increase in length; veligers become more mobile. Foot and eye development begins. The larval kidneys and visceral mass continue to be obvious; at this stage, the larval kidneys are positioned anterior of the mantle edge and the visceral mass is positioned just posterior of it, inside the mantle cavity. Each veliger has an average length of $784 \mu \mathrm{m}$ (range 660-910 $\mu \mathrm{m}$ ). Developing embryos retain the characteristics of the veliger stage for approximately 12 days (Fig. 2d; Table 1). 


\section{Pediveliger}

At the pediveliger stage, the protoconch (larval shell) thickens and begins to colour very slightly as it becomes pigmented and the siphonal groove forms. The first whorl also becomes obvious in the shell. The velar lobes continue to increase in size and become more defined. The foot and eyes also become more distinct and the tentacles develop. The larval kidneys are still present but are less pronounced and darker in colour. The visceral mass remains obvious through the thin shell. Each pediveliger has an average length of $800 \mu \mathrm{m}$ (range $720-870 \mu \mathrm{m}$ ). Developing embryos retain the characteristics of the pediveliger stage for approximately 12 days (Fig. 2e; Table 1).

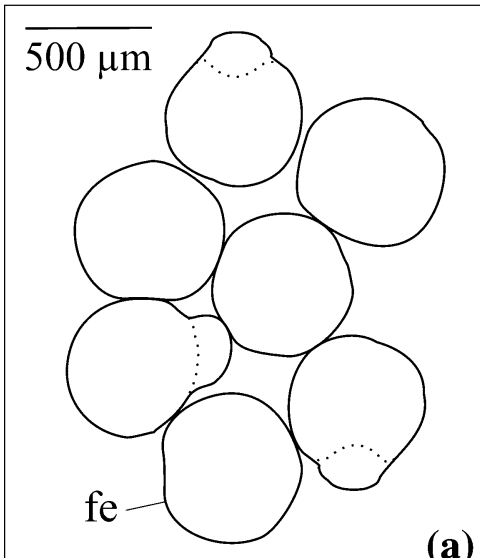

(a)

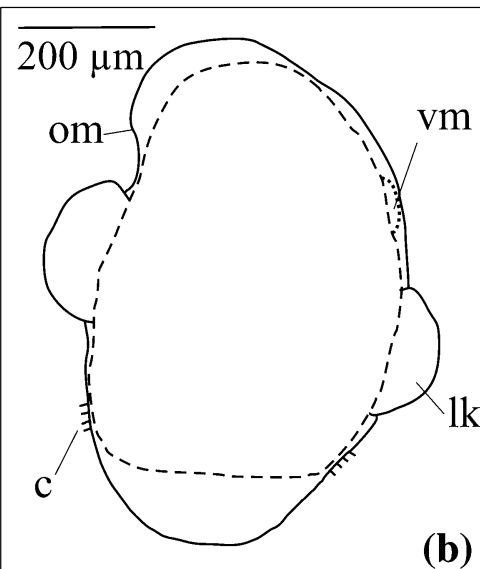

(b)
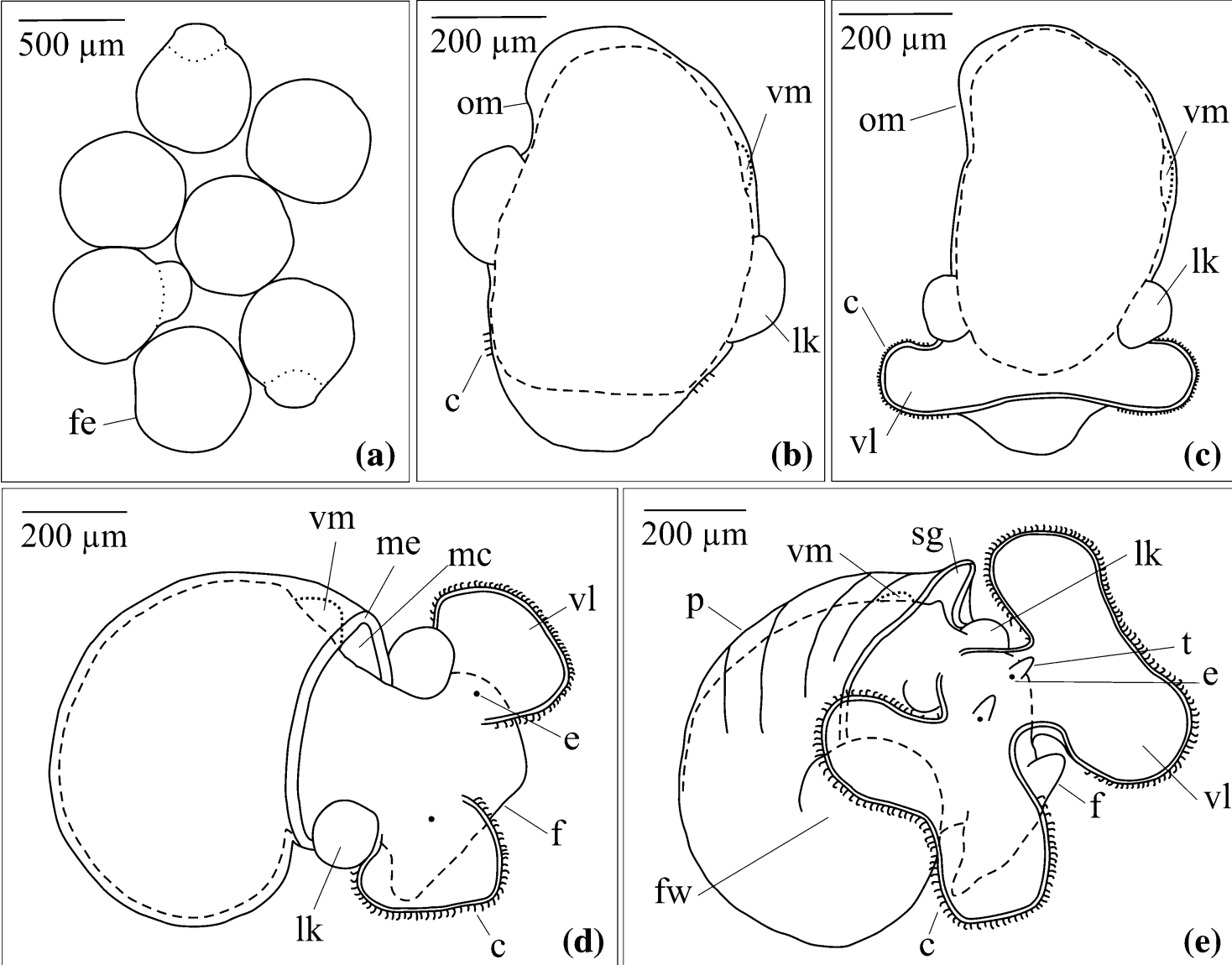

(d)
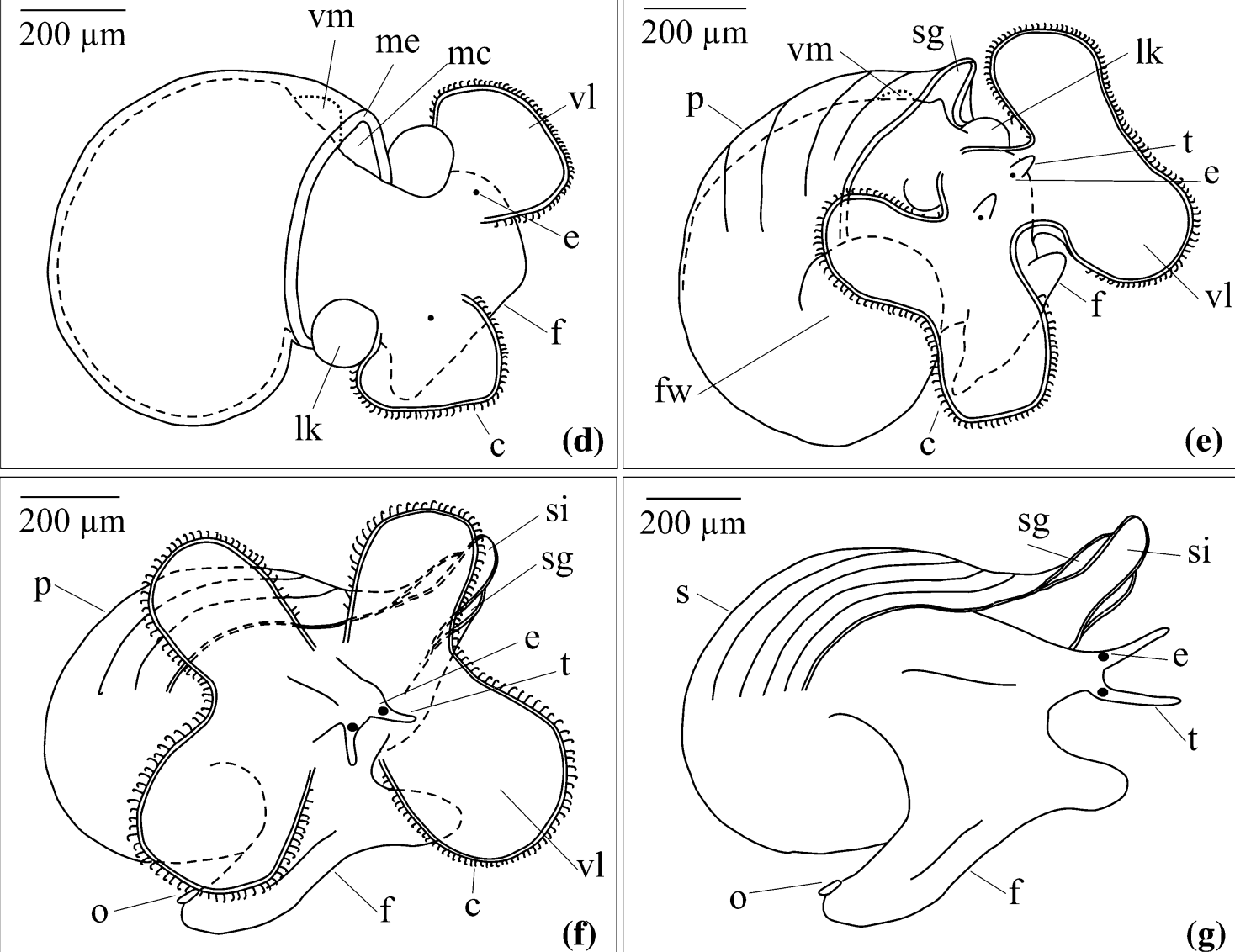

Fig. 2 Intracapsular developmental stages of Ocenebra erinaceus. a fertilized eggs/embryos, b trochophore, c early veliger, d veliger, e pediveliger, $\mathbf{f}$ late pediveliger/swimming late-pediveliger, and $\mathbf{g}$ prehatching juvenile/hatching juvenile (crawling). $f e$ fertilized egg/

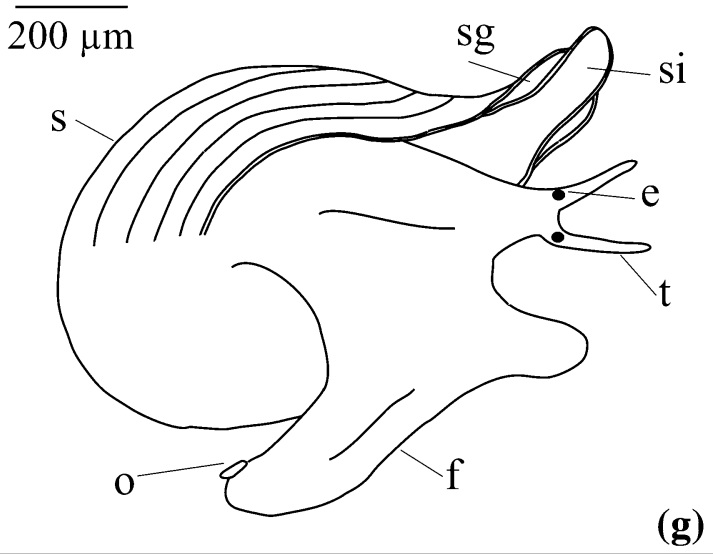

embryo, om outer membrane, $v m$ visceral mass, $c$ cilia, $l k$ larval kidney, $v l$ velar lobe, $m e$ mantle edge, $m c$ mantle cavity, $e$ eye, $f$ foot, $f w$ first whorl, $p$ protoconch, $s g$ siphonal groove, $t$ tentacle, $o$ operculum, si siphon, $s$ shell 
Table 1 Developmental periods for intracapsular development in Ocenebra erinaceus from the south coast of England $\left(50^{\circ} 39^{\prime} \mathrm{N}, 001^{\circ} 37^{\prime} \mathrm{W}\right)$ at $15{ }^{\circ} \mathrm{C}$

\begin{tabular}{|c|c|c|c|c|c|c|}
\hline Ontogenetic stage & $\begin{array}{l}\text { Mean time in days spent } \\
\text { at each stage (individual) }\end{array}$ & $\begin{array}{l}\text { Time at developmental } \\
\text { stage in days (whole egg } \\
\text { mass) }\end{array}$ & $\begin{array}{l}\text { Mean size } \\
(\mu \mathrm{m} \pm \mathrm{SE})\end{array}$ & $\begin{array}{l}\text { Mean number } \\
\text { per capsule } \\
( \pm \mathrm{SE})\end{array}$ & $n$ & $n$ (Capsules) \\
\hline Fertilized egg & 16 & $0-18$ & $587( \pm 3)$ & $48.2( \pm 2.14)$ & 2170 & 45 \\
\hline Trochophore & 4 & $16-23$ & $717( \pm 4)$ & $43.8( \pm 2.82)$ & 482 & 11 \\
\hline Early veliger & 8 & $19-32$ & $754( \pm 5)$ & $41.4( \pm 5.15)$ & 455 & 11 \\
\hline Veliger & 12 & $27-48$ & $784( \pm 5)$ & $44.3( \pm 2.89)$ & 1063 & 24 \\
\hline Pediveliger & 12 & $41-56$ & $800( \pm 5)$ & $44.2( \pm 2.57)$ & 795 & 18 \\
\hline $\begin{array}{l}\text { Late pediveliger/pre- } \\
\text { hatching juvenile }\end{array}$ & 12 & $50-69$ & $\begin{array}{l}849( \pm 5) \\
(850 \pm 6)^{\mathrm{a}} \\
(847 \pm 6)^{\mathrm{b}}\end{array}$ & $45.9( \pm 1.49)$ & $\begin{array}{l}1698 \\
\left(1003^{\mathrm{a}}\right) \\
\left(695^{\mathrm{b}}\right)\end{array}$ & 37 \\
\hline $\begin{array}{l}\text { Hatching: swimming late- } \\
\text { pediveliger/crawling } \\
\text { juvenile }\end{array}$ & $\mathrm{n} / \mathrm{a}$ & $59-69$ & $\begin{array}{l}856( \pm 7) \\
(855 \pm 8)^{\mathrm{c}} \\
(856 \pm 5)^{\mathrm{d}}\end{array}$ & $\begin{array}{l}44.6( \pm 1.80) \\
(6 \pm 4.6)^{\mathrm{c}} \\
(38.6 \pm 9.3)^{\mathrm{d}}\end{array}$ & $\begin{array}{l}714 \\
\left(345^{\mathrm{c}}\right) \\
\left(369^{\mathrm{d}}\right)\end{array}$ & 16 \\
\hline
\end{tabular}

Mean size (measured along longest axis) at each ontogenetic stage is displayed $(\mu \mathrm{m})$. Each measurement was determined from 100 individuals measured from a minimum of 10 capsules. $n$ dictates total number of individuals examined for ontogenetic stage. $n$ (capsules) dictates number of capsules that were examined at each stage and that individuals were measured from. Where n/a is stated, value was inapplicable

${ }^{\text {a }}$ Late pediveliger

${ }^{\mathrm{b}}$ Pre-hatching juvenile

c Swimming late-pediveliger

${ }^{\mathrm{d}}$ Crawling juvenile

\section{Late pediveliger/pre-hatching juvenile}

As embryos reach this stage, development becomes asynchronous within each capsule. Some individuals retain pronounced velar lobes throughout this stage (late pediveligers), while other individuals lose them completely and become pre-hatching juveniles. The loss of velar lobes indicates the disappearance of the remaining larval traits and the metamorphosis from larval stage to juvenile stage. In all individuals, the protoconch/shell thickens and becomes a little more pigmented, but remains semi-transparent. The siphonal groove becomes more defined and the siphon forms. The foot, tentacles, and eyes also become more prominent although all of these features are noticeably more pronounced in individuals that lack velar lobes (pre-hatching juveniles). The operculum develops on the foot. The larval kidneys disappear. There is no difference in size between late pediveliger and pre-hatching juveniles (two-sample $t$ test, $p=0.993$ ). Each individual has an average length of $849 \mu \mathrm{m}$ (range 740-930 $\mu \mathrm{m}$ ). Developing embryos retain the characteristics of late pediveliger or pre-hatching juveniles for approximately 12 days prior to hatching (Fig. 2f, g; Table 1). The number of individuals retaining velar lobes reduces gradually during this period.
Hatching: swimming late-pediveliger/crawling juvenile

All of the features described for pre-hatching juveniles and late pediveligers become more pronounced. At hatching, individuals emerge through the plug on the top of the egg capsule, when the mucus bung that seals the capsule throughout development dissolves. Most individuals hatch as crawling juveniles, but some hatch as swimming latepediveligers hatch with pronounced velar lobes. Swimming late-pediveligers are negatively buoyant but can move rapidly upwards in the water column when beating their velar lobes. Individuals hatching as crawling juveniles lack this swimming stage (Figs. 1c-e, 2f, g; Table 1). There is no difference in size between crawling juveniles and swimming late-pediveligers (two-sample $t$ test, $p=0.928$ ); individuals are identical in appearance, apart from the presence of velar lobes. They have an average length of $856 \mu \mathrm{m}$ (range $710-1040 \mu \mathrm{m}$ ).

\section{Dispersal polymorphism}

Approximately $14 \%$ of individuals from each capsule hatched as swimming late-pediveligers bearing full velar lobes (range $2-36 \%$ or 1-17 individuals per capsule, mean 6 individuals) (Table 1). The remaining $86 \%$ hatched as 
crawling juveniles. Swimming late-pediveligers moved actively but without obvious direction, until the velar lobes reduced and disappeared. They continued to swim actively for up to $72 \mathrm{~h}$ after hatching, although most settled and began crawling within approximately $24 \mathrm{~h}$; only $2 \%$ of individuals remained as a swimming late-pediveliger after 24 h (Fig. 3b).

\section{Embryonic development and intracapsular contents}

Each egg capsule took between 59 and 69 days to complete intracapsular development (Table 1). Between egg masses, development was asynchronous by up to 4 days initially and by up to 10 days by hatching. Within each egg mass, development was asynchronous by 1 or 2 days. Within each capsule, development was synchronous initially but became asynchronous by the late-pediveliger/pre-hatching juvenile stage. Every embryo developed, and there were no nurse eggs present. Embryos initially increased in size quite rapidly. Growth then slowed and became relatively linear from the early veliger stage throughout the remainder of development (Fig. 3a). Occasionally, one individual was observed at hatching that appeared to have used up all of its energetic reserves and was completely transparent, with no obvious internal content; these individuals appeared to be slightly retarded in development.

Each female laid an average of 21 egg capsules of lengths ranging from 5.78 to $10.97 \mathrm{~mm}$ (mean $8.55 \mathrm{~mm} \pm 0.08 \mathrm{SE}$ ). The number of fertilized eggs per capsule averaged 48.2, giving an approximate laying effort of 1012 fertilized eggs per female. The number of late pediveligers/pre-hatching juveniles per capsule averaged 45.9 (Table 1). An unpaired $t$ test indicated there to be no difference between number of fertilized eggs and number of late pediveliger/pre-hatching juveniles $(p=0.372)$. Regression analysis indicated there to be a significant relationship between capsule volume and the number of fertilized eggs per capsule $\left(r^{2}=0.1524 ; p<0.001\right)$.

\section{Discussion}

\section{Embryonic development and intracapsular contents}

The intracapsular development of $O$. erinaceus has never been fully described, although several previous studies have commented on aspects of it. The distribution of $O$. erinaceus ranges from the Shetland Islands, north of Scotland, to Greece and the Azores (http://iobis.org/map per/). The species is, however, most prevalent in waters around southern England and northern France, and reproduction and development have only been commented on for these areas (e.g. Hancock 1960; Gibbs 1996; Martel

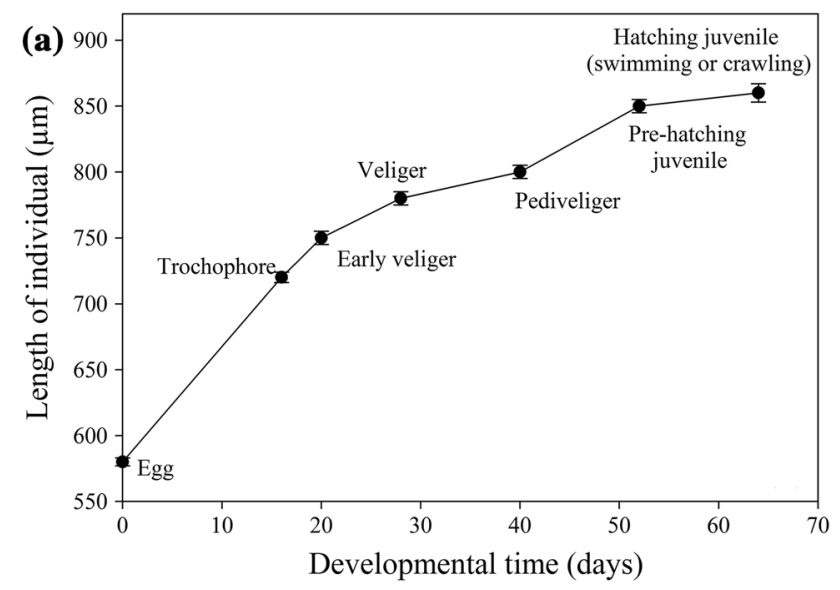

(b)

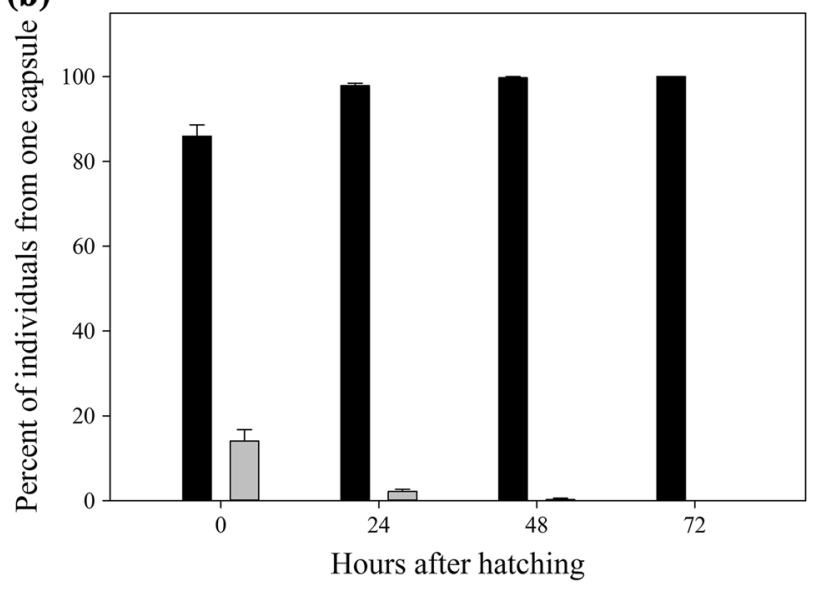

Fig. 3 a Change in size of Ocenebra erinaceus embryos during intracapsular development. Measurements taken along longest axis. Size displayed is mean length of individual at each stage in $\mu \mathrm{m}$. For each mean, $n=100$. b Percent of individuals from each capsule crawling (black) and swimming (grey) during first $72 \mathrm{~h}$ following hatching. Error bars indicate standard error

et al. 2004). In the present study, we observed egg laying during May, when water temperatures ranged between 14 and $16{ }^{\circ} \mathrm{C}$ (authors, pers. obs.). A similar period for egg laying in $O$. erinaceus has previously been reported although the temperature at spawning appears to vary. Over three successive years, Hancock (1960) observed egg laying to occur in April and May, once water temperatures reached $10-11^{\circ} \mathrm{C}$, whereas Gibbs (1996) successfully induced spawning in this species during February and March, and by artificially increasing water temperatures to $10-15{ }^{\circ} \mathrm{C}$. These results suggest that spawning is-at least in part-dependent on temperature. Other seasonal effects such as light or food availability may also affect spawning.

The number of egg capsules per female (mean 21) for $O$. erinaceus observed in the current study was similar to figures reported by Gibbs [mean 15 capsules per female (1996)] and Martel et al. [mean 24 capsules per female (2004)] but lower than those reported by Hancock [mean 
38 capsules per female (1960)]. The earlier study (Hancock 1960) indicates females laying at least $58 \%$ more capsules than any study from the last two decades. This general pattern is less apparent if we consider reproductive effort per female (number of capsules per female $\times$ number of eggs per capsule). In the present study, reproductive effort was approximately 1,012 embryos per female (21 capsules/ female * 48.2 eggs/capsule). By comparison, Martel et al. (2004) observed a reproductive effort of $\sim 1830$ eggs per female, Gibbs (1996) reported a reproductive effort of $\sim 476$ eggs per female, and Hancock (1960) reported a reproductive effort of $\sim 2356$ eggs per female. Some of these differences are likely caused by plasticity in maternal provisioning, but it is also possible that the differences are related to TBT pollution. The effects of TBT are still prevalent in O. erinaceus (Gibbs 2009), and prior to sterilization, females experience suppression in oogenesis (Huet et al. 1995). The lowest reproductive effort reported here (Gibbs 1996) was from Falmouth, UK, which was heavily polluted by TBT from the ship building industry located there (Gibbs 2009). In contrast, the highest reproductive effort (Hancock 1960) is from earlier studies, which also took place around Falmouth, UK, but were carried out prior to the widespread use of TBT. If the observed differences in reproductive effort are related to TBT, then the effort reported in this study and by Martel et al. (2004) suggest that populations of $O$. erinaceus are slowly recovering, but perhaps at different rates in different areas.

Another possible explanation for the reported differences in reproductive effort in $O$. erinaceus is variation in habitat. If this was an important factor, however, one would expect the results presented here to be to be similar to those of Hancock (1960), because both studies examined populations of $O$. erinaceus collected from the subtidal. In contrast, our results are most similar to those of Gibbs (1996) and Martel et al. (2004), who examined populations collected from the intertidal. This indicates that habitat type does not contribute to the between-study differences in reproductive effort.

During intracapsular development, the presence of nurse eggs is species specific (e.g. Spight 1976b). For O. erinaceus, past studies offer conflicting views on the source of nutrition available during development (Lebour 1937; Hancock 1956, 1960). In the present study, all embryos within a capsule completed development, indicating there to be no nurse eggs present. These results agree with those of Lebour (1937) but are contradictory to findings by Hancock (1956, 1960), who reported the presence of nurse eggs in the egg capsules of this species. This discrepancy is surprising; we found no reduction in embryos per capsule during development in the present study. Instead, we observed maternal partitioning of energetic reserves directly to each developing embryo. Additionally, although data are scant, besides Hancock $(1956,1960)$, no other authors have previously suggested the presence of nurse eggs in $O$. erinaceus egg capsules. It is, however, possible that embryos obtain some additional nutrition from the intracapsular fluid. We suggest that the early observations were due to a higher than average number of unhealthy cohorts per capsule. Alternatively, the reported differences could be considered a further example of plasticity in $O$. erinaceus. Environmental factors affect both maternal provisioning to embryos and the rate at which bioenergetic reserves are depleted during development (e.g. Crean and Marshall 2009; Smith et al. 2013). It is possible that variable environmental conditions are responsible for the reduction in the number of embryos per capsule observed by Hancock (1956, 1960). Under this scenario, an offset between maternal provisioning and energetic requirements for development may result in the occurrence of sibling cannibalism, a hypothesis that remains to be tested.

Duration of intracapsular development was approximately 59-69 days in the present study. Similar durations of 60 and 70 days have previously been reported by Hawkins and Hutchinson (1988) and Gibbs (1996), respectively, while a longer period of 84-91 days was reported by Hancock (1960). These differences are likely due to variations in temperature during development; the present study and that by Hawkins and Hutchinson (1988) maintained a temperature of $15^{\circ} \mathrm{C}$ throughout development and Gibbs (1996), of $13-16.5^{\circ} \mathrm{C}$. In contrast, Hancock (1960) indicated developmental temperature to be lower, at $10-11^{\circ} \mathrm{C}$, at least initially. Considering the known effects of temperature on development (e.g. Johns 1981; Sewell and Young 1999; Anger et al. 2004; Smith et al. 2013), differences in developmental period can be expected. Furthermore, and for the present investigation, it should also be noted that it is possible that hatching was delayed by a couple of hours or days due to a lack of current flow, which egg masses would typically experience in their natural environment.

In the present study, all embryos developed successfully and attained a similar size at hatching, with the exception of the occasional embryo with retarded development. The occurrence of the occasional retarded embryo, which lacks apparent internal content, is often observed during intracapsular development in gastropods (e.g. Cumplido et al. 2011; Smith and Thatje 2013a, b). Hatching sizes for $O$. erinaceus have previously been observed to range 800-1000 $\mu \mathrm{m}$ (Lebour 1937; Gibbs 1996), which is similar to the average $856 \mu \mathrm{m}$ size observed in this investigation.

There are similarities and differences between the intracapsular development of $O$. erinaceus and that of other species of Ocenebra. For example, like O. erinaceus, no 
nurse eggs are present during the intracapsular development of O. aciculata (Franc 1940). In contrast, nurse eggs are present during intracapsular development in $O$. japonica (Fotheringham 1971) and O. poulsoni (Amio 1963). Stage at hatching also varies; $O$. aciculata, O. inornatus, and $O$. japonica all hatch as crawling juveniles (Franc 1940; Fotheringham 1971; Martel et al. 2004), whereas $O$. poulsoni hatch as swimming veliger (Amio 1963). Finally, time to hatching also varies, and other species of Ocenebra typically have a shorter developmental period than $O$. erinaceus; hatching in $O$. aciculata occurs after approximately 46 days (Franc 1940), in O. poulsoni it occurs after approximately 21-28 days (Fotheringham 1971), and in O. japonica it occurs after 30 days (Amio 1963).

\section{Dispersal polymorphism}

Dispersal polymorphism offers a trade-off between the traditional modes of development (pelagic and benthic), which enables a species to take advantage of the benefits of both. Bet-hedging strategies such as this can maximize individual fitness, in particular in areas of environmental uncertainty, and may also facilitate rapid range expansion (Marshall et al. 2008; Krug 2009). While pelagic development offers a mechanism for broad dispersal, a decreased likelihood of inbreeding, and an increased ability to withstand local extinctions, benthic development instead facilitates rapid population growth and the potential for local adaptation within a population (Pechenik 1999; Grantham et al. 2003; O'Connor et al. 2007). The dispersal polymorphism we observed in $O$. erinaceus could be considered a model approach for development; the majority of offspring remain within the parental population, while a small proportion of offspring, instead, disperse to other areas. Additionally, because development is direct and the mother provides nutritional reserves, survival is likely to be high for all hatchlings. Dispersal polymorphism has rarely been described in marine invertebrates; it has been reported most commonly for opisthobranch gastropods (for review see Krug 2009), but has also recently been observed in another muricid gastropod, Hexaplex trunculus (Güler and Lök 2014). To our knowledge, dispersal polymorphism has not been reported in any other group of marine invertebrates and, until now, has not been described for any gastropod with encapsulated development, apart from $H$. trunculus. It should be noted, however, that this has previously been confused with poecilogony (Krug 2009). In contrast to O. erinaceus, where most ( $\sim 86 \%$ ) offspring hatched as crawling juveniles and the remaining few metamorphosed within 24-72 h of hatching, in H. trunculus, only a small number of offspring hatched as crawling juveniles and the majority spent a minimum of 2 days in the plankton prior to final metamorphosis (Güler and Lök 2014). The proportion of crawling juveniles to swimming late-pediveligers at hatching is most likely species-dependent, and therefore the differences observed between $O$. erinaceus and $H$. trunculus are not surprising. Differences may also be observed within a species; for example, in opisthobranch gastropods, the proportion of juveniles hatching with velar lobes has been shown to be dependent on temperature (Clemens-Seely and Phillips 2011). Temperature has long been recognized as a significant factor determining developmental rates in marine invertebrates (e.g. Johns 1981; Sewell and Young 1999; Anger et al. 2004; Smith et al. 2013), and for species exhibiting dispersal polymorphism, it is also likely to impact duration spent in the plankton. This may explain the differences in proportion of swimming late-pediveligers observed in the present study and by Gibbs (1996), who indicated all juveniles of $O$. erinaceus to experience a period in the plankton following development at temperatures ranging $10-15^{\circ} \mathrm{C}$, which would on average be cooler than the $15^{\circ} \mathrm{C}$ maintained in this study. Additionally, the earlier study indicated larvae to remain swimming for up to 5 days, as opposed to the 3 days observed here. It should be noted that, to date, dispersal polymorphism has not been reported in any other species of Ocenebra.

The dispersal polymorphism observed in O. erinaceus offers an ecological advantage that has rarely been reported in marine invertebrates. Flexibility in development and dispersal give offspring an opportunity to dominate in their parent population while simultaneously entering other populations. As a reproductive pattern, this allows $O$. erinaceus to potentially benefit from constant gene flow between populations, while ensuring the parent population continues to be sufficiently contributed to. The rapid colonization that dispersal polymorphism facilitates also offers this species an advantage with regard to colonizing new areas. Considering this, in the future, and as TBTinduced imposex becomes less prevalent in this species, $O$. erinaceus may once again become a serious problem for shellfisheries throughout its distribution.

Acknowledgments We thank the skipper and crew of $R V$ Callista for their help with sample collection. This work was supported by a grant from the Malacological Society to KES. AJR was supported by a Natural Environment Research Council PhD studentship.

\section{References}

Amio M (1963) A comparative embryology of marine gastropods, with ecological emphasis. J Shimonoseki Univ Fish 12:229-353

Anger K, Lovrich G, Thatje S et al (2004) Larval and early juvenile development of Lithodes santolla (Molina, 1782) (Decapoda: Anomura: Lithodidae) reared at different temperatures in the laboratory. J Exp Mar Biol Ecol 306:217-230 
Chia FS, Gibson G, Qian PY (1996) Poecilogony as a reproductive strategy of marine invertebrates. Oceanol Acta 19:203-208

Clemens-Seely K, Phillips NE (2011) Effects of temperature on hatching time and hatchling properties in a poecilogonous population of Haminoea zelandiae. Biol Bull 221:189-196

Collin R (2012) Temperature-mediated trade-offs and changes in lifehistory integration in two slipper limpets (Gastropoda: Calyptraeidae) with planktotrophic development. Biol J Linn Soc 106:763-775

Cowen RK, Sponaugle S (2009) Larval dispersal and marine population connectivity. Annu Rev Mar Sci 1:443-466

Crean AJ, Marshall DJ (2009) Coping with environmental uncertainty: dynamic bet hedging as a maternal effect. Phils Trans R Soc B 364:1087-1096

Cumplido M, Pappalardo P, Fernández M et al (2011) Embryonic development, feeding and intracapsular oxygen availability in Trophon geversianus (Gastropoda: Muricidae). J Molluscan Stud 77:429-436

Elliot EC, Cornell SJ (2012) Dispersal polymorphism and the speed of biological invasions. PLoS One 7(7):e40496

Fotheringham N (1971) Life history patterns of the littoral gastropods Shaskyus festivus (Hinds) and Ocenebra poulsoni Carpenter (Prosobranchia: Muricidae). Ecology 52:742-757

Franc A (1940) Recherches sur le developpement d'Ocenebra aciculate Lamarck. Biol Bull Fr Belg 74:327-345

Gibbs PE (1996) Oviduct malformation as a sterilising effect of tributyltin (TBT)-induced imposex in Ocenebra erinacea (Gastropoda: Muricidae). J Molluscan Stud 62:403-413

Gibbs PE (2009) Long-term tributyltin (TBT)-induced sterilization of neogastropods: persistence of effects in Ocenebra erinacea over 20 years in the vicinity of Falmouth (Cornwall, UK). J Mar Biol Assoc UK 89:135-138

Gibbs PE, Bebianno MJ, Coelho MR (1997) Evidence of the differential sensitivity of neogastropods to tributyltin (TBT) pollution with notes on a species (Columbella rustica) lacking the imposex response. Environ Technol 18:1219-1224

Grantham BA, Eckert GL, Shanks AL (2003) Dispersal potential of marine invertebrates in diverse habitats. Ecol Appl 13:108-116

Güler M, Lök A (2014) Embryonic development and intracapsular feeding in Hexaplex trunculus (Gastropoda: Muricidae). Mar Ecol 35:193-203

Hancock DA (1956) The structure of the capsule and the hatching process in Urosalpinx cinerca (Say). Proc Zool Soc Lond 127:565-589

Hancock DA (1960) The ecology of the molluscan enemies of the edible mollusc. Proc Malacol Soc Lond 34:123-143

Hawkins LE, Hutchinson S (1988) Egg capsule structure and hatching mechanism of Ocenebra erinacea (L.) (Prosobranchia: Muricidae). J Exp Mar Biol Ecol 119:269-283

Huet M, Fioroni P, Oehlmann J, Stroben E (1995) Comparison of imposex response in three prosobranch species. Hydrobiologia 309:29-35

Jablonski D (1986) Larval ecology and macroevolution in marine invertebrates. Bull Mar Sci 39:565-587

Johns DM (1981) Physiological studies on Cancer irroratus larvae. I. Effects of temperature and salinity on survival, development rate and size. Mar Ecol Prog Ser 5:75-83

Krug PJ (2007) Poecilogony and larval ecology in the gastropod genus Alderia*. Am Malacol Bull 23:99-111
Krug PJ (2009) Not my "type": larval dispersal dimorphisms and bethedging in Opisthobranch life histories. Biol Bull 216:355-372

Laing I, Spencer BE (2006) Bivalve cultivation: criteria for selecting a site. CEFAS science series technical report no. 136. Crown copyright, Norwich

Lebour MV (1937) The eggs and larvae of the British prosobranchs with special references to those living in the plankton. J Mar Biol Assoc UK 22:105-166

Marshall DJ, Bonduriansky R, Bussière LF (2008) Offspring size variation within broods as a bet-hedging strategy in unpredictable environments. Ecology 89:2506-2517

Martel C, Guarini JM, Blanchard G et al (2004) Invasion by the marine gastropod Ocinebrellus inornatus in France. III. Comparison of biological traits with the resident species Ocenebra erinacea. Mar Biol 146:93-102

O’Connor MI, Bruno JF, Gaines SD et al (2007) Temperature control of larval dispersal and the implications for marine ecology, evolution, and conservation. Proc Natl Acad Sci 104:1266-1271

Oehlmann J, Stroben E, Fioroni P (1992) The rough tingle Ocenebra erinacea (Neogastropoda: Muricidae): an exhibitor of imposex in comparison to Nucella lapillus. Helgol Meeresunters 46:311-328

Oehlmann J, Fioroni P, Stroben E, Markert B (1996) Tributyltin (TBT) effects on Ocinebrina aciculata (Gastropoda: Muricidae): imposex, development, sterilization, sex change and population decline. Sci Total Environ 188:205-223

Oyarzun FX, Strathmann RR (2011) Plasticity of hatching and the duration of planktonic development in marine invertebrates. Integr Comp Biol 51:81-90

Pechenik J (1979) Role of encapsulation in invertebrate life histories. Am Nat 114:859-870

Pechenik JA (1999) On the advantages and disadvantages of larval stages in benthic marine invertebrate life cycles. Mar Ecol Prog Ser 177:269-297

Poulin E, Boletzky SV, Féral J-P (2001) Combined ecological factors permit classification of developmental patterns in benthic marine invertebrates: a discussion note. J Exp Mar Biol Ecol 257:109-115

Sewell MA, Young CM (1999) Temperature limits to fertilization and early development in the tropical sea urchin Echinometra lucunter. J Exp Mar Biol Ecol 236:291-305

Smith KE, Thatje S (2013a) Nurse egg consumption and intracapsular development in the common whelk Buccinum undatum (Linnaeus 1758). Helgol Mar Res 67:109-120

Smith KE, Thatje S (2013b) The subtle intracapsular survival of the fittest: maternal investment, sibling conflict or environmental effects? Ecology 94:2263-2274

Smith KE, Thatje S, Hauton C (2013) Effects of temperature on early ontogeny in the common whelk Buccinum undatum (L. 1785); bioenergetics, nurse egg partitioning and developmental success. J Sea Res 79:32-39

Spight TM (1976) Hatching size and the distribution of nurse eggs among prosobranch embryos. Biol Bull 150:491-499

Toonen RJ, Pawlik JR (2001) Foundations of gregariousness: a dispersal polymorphism among the planktonic larvae of a marine invertebrate. Evolution 55:2439-2454

Vance RR (1973) On reproductive strategies in marine benthic invertebrates. Am Nat 107:339-352 